\title{
SÕNA
}

\section{SARN JA SARNANE}

\author{
LEMBIT VABA
}

$\mathrm{E}$ esti sõnale sarn 'põsenukk', mis esineb tavaliselt liitsõnades põselsarn 'sarn, põsenukk', sarnalluu 'ANAT mitmeharuline, sarnakaare ja silmakoopa külgseina moodustamises osalev luu (os zygomaticum)' (EKSS) pole seni leitud rahuldavat etümoloogiat. Sama tuleb tõdeda ka sarnane 'välimuses $\mathrm{v}$ mingis muus suhtes rohkete ühetaoliseks tegevate ühisjoontega; KÕNEK säärane, seesugune, selline, niisugune' (EKSS) kohta.

\section{sarn on lõunaeesti sõna}

Ehkki tänapäeval kuulub sarn endastmõistetavalt põhjaeestilisse ühis- ja kirjakeelde, on sõna murdelevikult selgelt lõunaeestiline. VMS-i järgi on sarna levikupilt selline: Kod, MMg, Hel, Ran, Puh, Nõo, TMr, Võn, Kam, Ote, San, Kan, Urv, Krl, Har, Rõu, Plv, Vas, Räp, Se, Lut. EKMS II: 708 sub Luu; EKMS II: 1236 sub Nägu on esitanud levikupildi üldistaval kujul: Lõuna-Tartumaa, Hel, Põhja-Võrumaa. Eranditult lõunaeesti levikust kõnelevad ka ERA rahvalaulud; mõned näited: Maha pessi ma musta rihe / Maha aie haganedse / Maha tougassi ma tolmutse / Es jä̈̈ utsu otsa pääle / Põrmu põsesarna pääle (San Laatre); Tuimal neiul tutsaku juusse, / laisal lag'a lõvvaots, / vihatsel vereva põsesarna, / kurjal musta silmäkolmo (Krl V.-Antsla); Lätsi ma vanale mehele, / Inne aigu armetule, / Anni suud, salve sarna (Vas); Mii oleme iks vaese latse, / Selle silmä vesitse / Selle sarna sadehitse (Räp); Oma hot' silma mul ikutsõ / Sarna iks sadajatsõ (Se Petseri). Põlvast on kirja pandud vanasõna Sööjal vesi sarna pääl, põdejal põski pääl (Vanasõnaraamat: 159). Eesti leksikograafia noteerib sarna siiski alles alates Wiedemannist (1973: 1007): sarn G. sarna (d) 'Wangenknochen', põze-s. dass. Põhjaeesti murdekeeles tähistab sarna peamiselt nukk/põsenukk, Lääne-Eesti saartel ja mitmel pool Lääne-Eestis aga sasu, sasi : sase (EKMS II: 1238 sub Nägu; VMS). Heinrich Rosenplänter on oma nn tõlkeharjutustes kasutanud liitsõna palepõsed: Kõrwe jurest, seält kus loua liikmed on ning kust louad andwad kin̄ni ja lahti käia, hakkawad louapärrad. Juba seältgi hakkawad palled, ja need kõrgemad muhhud palle peäl hütakse pallepõssed (Rosenplänter 1818: 19). Wiedemanni sõnaraamatust leiame veel järgmised teated: pale-końt 'Backenknochen, Kinnlade' (sub końt), paleluu, palgeluu 'Wangenbein, Backenknochen' (sub lū), samuti kõrwa-jūred 'Backenknochen' (sub jūŕ), mille Jakob Hurt on märkinud veaks resp. ebatäpsuseks. 


\section{sarna tulek kirjakeelde}

sarna tulekut eesti kirjakeelde pole selles loos võimalik täpsemalt jälgida. Allpool esitan vaid mõned tähelepanekud. Ootuspäraselt leiame sarna Wiedemanni sõnaraamatu põhjal koostatud Margus Salemi (1890: 347) eesti-vene sõnaraamatust: sarn : sarna, põsesarn 'скулова́я кость', samuti Johan Jurkatame (1904: 887) vene-eesti sõnaraamatust kõrvuti põsenukiga: cкyлá 'põsenukk, -sarn', aga скула́стый vasteks on 'suurte, kõrgete põsenukkidega' ja скулово́й', скульно́й puhul 'põsenuki-'. Võimalik, et lõunaeestiline sarn on hakanud laiemalt levima arstiteadusliku kirjanduse kaudu, kuid XIX sajandi lõpu ja XX sajandi alguse asjaomases kirjanduses sarna ega sarnaluud veel ei kasutata, seda tähistab põse luu (Hellat 1891: 21), põseluu (Hellat 1913: 25), põsenukk : põsenuki lihas (Niggol 1914: 50). EKÕS-i ilmumisest alates (1918) leiab sarn tee juba kõikidesse üldsõnaraamatutesse. EÕS (III: 1268) esitab sõna sarn, samuti arvukalt liitsõnu ja tuletisi: sarn (= põsenukk, cкyлa, sarnaluu), sarnalerk, sarnalhari $=$ põsehari, sarnaljätke, sarnalkaar $=$ põse $(l u u) k a a r$, sarnallihas, sarnalluu jne. Sõna kohast tänapäeva eesti meditsiinisõnavaras annab ettekujutuse LEVM: gena $=$ sarn $[$ sarna $]$ (põsenukk), mala = põsk, sarn, zygoma = sügoom, sarn, põsenukk.

\section{sarn ei ole tuletis}

Muud läänemeresoome, samuti kaugemad sugulaskeeled ei tunne sarna; seda tähistab nt liivi keeles posklu, vadja keeles silmäluu, soome keeles poskipää, tverikarjalas haben, l'ewgapieli i või ka šokka, aunusekarjalas šokku, vepsa keeles sazopäd pl, čokıu.

Julius Mägiste (1953: 369; EEW IX: 2708) on sarna (mitme küsimärgiga) sidunud läänemeresoome keelte põhjarühma sarvena-perega: sm sarvena / sarven / sarvana, samuti sarventa / sarvento / sarvanto jt 'vaagen, puusad, puus (hobuse, lehma), puusanukk, puusaköber, puusaluu, puusakont', is sarvena 'puus', krj sarvena/sarvana/šarvena/šarvana jt, särvinäzlluu 'puusaluu, puusakont'. Läänemeresoome sarvena arvatakse olevat na-liitega tuletis sarvi-sõnast (Hakulinen 1968: 112; SKES IV: 977; Hahmo 1994: 134-136). Mägiste on eesti keeles oletanud häälikuarengut *sarvena $>{ }^{*} \operatorname{sarvna}>\operatorname{sarn}(a)$, kus sisekao tõttu tekkinud ebaharilikust konsonantühendist -rvn- kadus $v$. Läänemeresoome sõnade algne tähendus võis Mägiste järgi olla 'sarvetaoliselt esiletungiv põseluu resp. niudeluu hari / die hornartig hervorstechende Wangenknochen bzw. Hüftbeinspitze'. Kirjeldatud häälikuareng on selliste häälikuehitusega tuletistes ja nendega muganenud (vanemates) laensõnades küll võimalik, nagu juhtudel eL (Wied) ahn : ahne = ahven, eL (Wied) pähn : pähnä = pähken 'pähkel', eL Akn (Clare 1730, tsit. Ariste 2010: 137 järgi) = aken, kuid nende kõrval on alati ka muid häälikuvariante: eL ahun, ahnõ? = ahven jt, eL pähen, pähken, pähe?, pähi jt, S, eL ake, eL akõn = aken. On tähelepanuväärne, et sarnal pole samalaadseid ootuspäraseid häälikuvariante, mis sunnib arvama, et sel pole olnudki kolmesilbilist algkuju, mis looks eelduse sellisteks arenguteks.

Suurem probleem on minu arvates aga selles, et meie piirkonna muud keeled ei toeta semantilise arengu oletust 'puusaluu' > 'põseluu' ega vastupidistki. Õhkõrna tuge on arvatud pakkuvat Kihnu sarn : sarna 'puusakont, puusaluu' 
(EKMS II: 708 sub Luu), millele on rõhunud nt Sirkka-Liisa Hahmo (1994: 135), asudes toetama Mägiste etümoloogiat. Alo Raun (1982: 153) ja Eino Koponen (1998: 164) peavad sarna etümoloogiat ebaselgeks.

\section{sarnal on vasteid slaavi keeltes}

Ülalkirjeldatud raskused langevad ära, kui esitada sarnale laenuetümoloogia. Võimalik laenualus on pleofooniaeelne slaavi häälikkuju *skorńa, mille jätkajaid leidub nii ida-, lõuna- kui ka lääneslaavi keeltes: vvn скоронь f, скороня $\mathrm{f}$ 'meelekoht, oim', скорыния id., vn скоронь f 'meelekoht, oim', murd скорынья́ 'lõualuu, lõuapool, lõuapära, lõug', скоро́нный 'oimu-', kirikuslaavi (vene ja serbia redaktsioonid) скрания (-ья) 'põsk, pale; meelekoht, oim; otsmik, otsaesine, laup; lõuapära, lõug', скрань 'põsk, pale; põsenukk, sarn; näo külgmine osa; lõug, lõuapära', slo škraň, škraňa 'põsesarn, põsenukk, lõualuu', skranja, kranj 'lõug', tš skráň, murd skráně, škraň, skřaň, škřaň 'meelekoht, oim; (murd) ülemine lõualuu (sarnaluu)', pol skroń f'meelekoht, oim, alumine lõualuu', skronie pl 'pea', üsrb skroń, asrb škŕono n, škŕona, skrońa 'meelekoht, oim; põsesarn, põsenukk', slvn skrânj f, skránja f '(põse)sarn, põsenukk; lõualuu, lõuapool, lõuapära, lõug', skrânje n 'meelekoht, oim' (Vasmer III: 653; Machek 1968: 548; Rejzek 2001: 577; SRJA 25: 15-16). Slaavi sõnapere võimalikud kaugemad vasted on visl hvarmr m 'silmalaug', lad parma 'väike ümmargune kilp' < gallia *parma, vrd uelsi parfa 'soomusrüü naast' (Vasmer III: 653), keskiiri cern $\mathrm{f}$ 'supitirin, praevaagen', isl hvörn 'kalapea luud', nr murd hvann id., gt haírnei $\mathrm{f}$ 'kolju, pealuu', visl hverna f 'keedunõu' (IEW II: 642), tohaari B krāñi 'mingi osa peast' (Rejzek 2001: 577); võimalik indoeuroopa algkeele etümon on * $(s) k^{u} e r-n$ 'pealuu, osa peast' (IEW II: 642; Rejzek 2001: 577).

\section{Häälikulise ja morfoloogilise substitutsiooni küsimusi}

Esitatud laenuetümoloogia eeldab häälikusubstitutsiooni $s k$ - $>s$-. Sellise kohanemise kohta on vähe teateid, mille üheks põhjuseks on asjaolu, et teise konsonandi väljalangemist sõnaalgulises konsonantühendis pole peetud tõenäoliseks, mistõttu selliseid laenujuhte on vähe esile tulnud. Hartmut Katzi (1990: 27-28) järgi esindavad häälikulist kohanemist $s k$ - $>s$ - oletatavasti alggermaani laenuallikast saadud lms *sitta 'sitt' < *skitta, sm sato 'saak, viljalõikus' < *skadan- 'see, mis välja hüppab', lms *saari < *skarja- 'rannalähedane kaljusaareke, kaljulaid / Schäre', sm sammio 'tõrs, toober' < *skammjōn; muid sõnaalgulise konsonantühendi substitutsioonijuhte $\mathrm{C}_{1} \mathrm{C}_{2} \mathrm{~V}->\mathrm{C}_{1} \mathrm{~V}$ - eesti keele balti, saksa ja vene laenudes vt Vaba 2002: 394-395.

On tähelepanuväärne, et tüvesisese morfeemipiirita $r n$-järjendiga eesti tüved on valdavalt laenulised (vt Vaba 1997: 141-142), mis samuti kallutavad laenuetümoloogia poole. EES esitab 34 rn-järjendiga tüve, millest vähemalt 25 , s.o $74 \%$ on laentüved. Päritolult jagunevad need järgmiselt: aarja laenud ? põrn (siseelund) + ? põrnitsema + ? põrnikas, tarn, ? ternes; balti laen - hernes; vene laenud - ? surnuk 'süstik', sõrnik; germaani laenud - hõrnas 'jõeforell' + ärn 'harjus', ? kurn (nõu) + kurnama, ? kõrne; skandinaavia laen - türn(puu); alamsaksa laenud - karn / kärn 'lihakauplus', kirn, torn (ehitis), värnits / ver- 
nits; saksa laenud - arnika / ärnika (taim), kärn ${ }^{1}$ 'valuvormi siseosa', $k a ̈ r n n^{2}$ (tööriist), kärner, ornung 'kord', pirn, torn (tööriist), turnima, tärn 'kujund vms'; prantsuse laen - morn. Muud juhtumid jagunevad nii: soome-ugri tüvi kärn 'koorik, korp'; läänemeresoome tüved - hirnuma, pärn, varn (pigem siiski eventuaalne balti resp. slaavi laen, vt Vaba 2014), virn (taim), orrn; tehistüvi tarnima; ebaselged - kurn 'viskemängu pulk', virn 'hunnik'. EES-i materjalis domineerivad germaani keeltest laenatud $r n$-tüved, ent vaateväljast kõrvale jäänud vananenud sõnavara, murdesõnavara vms on esindatud rohkete rnjärjendit sisaldavate laentüvedega: selgub, et ka vene laenude hulgas on neid väga arvukalt, nt karnits 'õõnesmõõt', kurnik 'munakook', marna 'tume, sünge', mernik 'suur nõu', parnik 'kasvuhoone', (polu)vernik, sernik 'noodaomanik', smirna 'korda, joonde', tsärnil 'tindipott', turnoi 'lollakas, juhm', vorna 'hoolas, tubli, kärme' jt (vene laenud, vt Must 2000). $r n$-järjendiga tüved on üsna arvukalt esindatud murdelise taustaga onomatopoeetilis-deskriptiivses sõnavaras, nagu hörnümä 'naerma, hirnuma', kirnama 'nuruma', parnama, plärnama 'lobisema', pärnama 'plärama', turnama 'puristama, pruuskama' (VMS).

Läänemeresoome keelte vene laene iseloomustab $a / o$ esinemuse suur kirevus. Vana- ehk muinasvene laenude avatud $a$-list $o$-d korvab teatavasti $a$, nagu juhtudel aken < vvn окъно, vn окнó, papp < vvn nonъ, vn non, vaba < vvn свобода, vn свобо́да, vaеn < vvn воина, vn война́. Sellist substitutsiooni esindab ka käsiteldav laenujuhtum. Vene $a$ - ja $\Omega$-, osaliselt ka $H b$-lõpulised naissoost nimisõnad on vanema kihistuse laenudes morfoloogiliselt kohanenud eesti $A$-tüveliste nimisõnadega, nagu eL truśsin : trusina 'nootkond' < Әружи́на, krupen, - $a$ 'kartuli-tangusupp jt' < vn крупе́ня/ крупе́нь, t'sasson, - a 'palvemaja, kabel' < часовня, pälin, -a, pällin : pälinä jt 'koirohi' < пелунь jt (vt Must 2000: 532-534). Analoogilise kohanemise on läbi teinud ka sarn : sarna.

\section{sarnane}

Ühe seletuse järgi on omadussõna sarnane 'välimuses v mingis muus suhtes rohkete ühetaoliseks tegevate ühisjoontega' (EKSS) ja adverb sarna 'FOLK, VAN kellegi, millegi viisi, moodi' tuletatud põsenukki tähistavast sarn-tüvest. Selle etümoloogia toetuseks on Eino Koponen juhtinud tähelepanu samalaadsele tähendussuhtele soome keeles: sm muoto 'vorm, kuju; rivi; näojooned, ilme, nägu' ja sm muotoinen 'millegi kujuline; sarnane, taoline' (Koponen 1998: 164). Samalaadseid semantilisi seoseid võib leida nt ka germaani jt keeltest, vt i-e *līg- 'keha, kuju, sarnane, samasugune' (IEW II: 667). Selle etümoloogia usutavuse küsimärgistab sarna ajalooliselt lõunaeestiline levik, sarnane levila on aga üle-eestiline.

Teise seletuse kohaselt on sarnane läänemeresoome-permi või soome-ugri tüvi, mille jätkajad läänemeresoome keeltes on vdj saarnaaja '(lahkusu) jutlustaja', sm saarna 'jutlus', is saarnata 'jutlustada', krj šoarna, krjA suarnu 'muinasjutt', krjL suarne 'muinasjutt', vps sarn id. (Mägiste 1953: 365-369; SKES IV: 938-939; EEW IX: 2708-2709; Raun 1982: 153 [seob küsimärgiga]; SSA 2: 139; EES: 461 sub sarnane). Ee sarnane ja sm saarna jt on 1877. aastal kõrvutanud Soome luuletaja ja keelemees Arvid Genetz (vt SSA 3: 139 sub saarna). Kõrvutuse semantilist seost on korduvalt põhjendanud Mägiste (1953: 365-369; EEW IX: 2708-2709): tema arvates on sarnane algne sisu 
olnud 'kõnes olev, kõnes olevale sarnane/in Rede stehend, dem in Rede Stehenen ähnlich'.

Sõnatüvel on ka pikavokaalne variant: sārn : sārna $(\mathrm{d})=$ sārnaus $(\mathrm{d})=$ sarnadus, sārnane (S) = sarnane (Wied), Kirde-Harjumaa, Põhja-Virumaa saarnane 'sarnane' (EKMS III: 733); Lääne-Ingeri rahvalaulude saarnallinen 'kaltainen, tapainen' on tõenäoliselt eesti laen (SKES IV: 939; EEW IX: 2709). Sõna kohta leidub kirjasõnas teateid juba varakult: (Müller) kuma Achio sarnax 'gleich einem heissen Ofen' (vt EEW IX: 2708), (Göseken 1660: 103) Ähnlig / Sharnane (vt EKMS III: 734).

Artikkel on valminud autori vabal tahtel ega seostu mitte ühegi rahastatava projektiga.

\section{Võrgumaterjalid}

EKSS = Eesti keele seletav sõnaraamat. http://www.eki.ee/dict/ekss

ERA = Eesti rahvalaulude andmebaas. http://www.folklore.ee/regilaul/andmebaas

\section{Kirjandus}

A r is te, Paul 2010. Sõnalaenulõbu. Koost Peeter Olesk. (Eesti mõttelugu 93.) Tartu: Ilmamaa.

EES = Eesti etümoloogiasõnaraamat. Koost ja toim Iris Metsmägi, Meeli Sedrik, Sven-Erik Soosaar. Peatoim I. Metsmägi. Tallinn: Eesti Keele Sihtasutus, 2012. EEW = Julius Mägiste 2000. Estnisches etymologisches Wörterbuch I-XII. Helsinki: Finnisch-Ugrische Gesellschaft.

EKMS = Andrus Saareste 1958. Eesti keele mõisteline sõnaraamat I-IV. Stockholm: Vaba Eesti.

EKSS $=$ Eesti keele seletav sõnaraamat 1-6. Toim Margit Langemets, Mai Tiits, Tiia Valdre, Leidi Veskis, Ülle Viks, Piret Voll. Tallinn: Eesti Keele Sihtasutus, 2009.

EKÕS = Eesti keele õigekirjutuse-sõnaraamat. Eesti Kirjanduse Seltsi wäljaanne. Tallinnas: K.-Ü. „Rahwaülikooli” kirjastus, 1918.

EÕS = Eesti õigekeelsuse-sõnaraamat I-III. Tartus: Eesti Kirjanduse Seltsi kirjastus, 1937.

G ö s e k e n, Heinrich 1660. Manuductio ad Linguam Oesthonicam. Anführung zur Öhstnischen Sprache. Reval: Gedruckt und verlegt von Adolph Simon, Gymnasii Buchdr.

H a h m o, Sirkka-Liisa 1994. Grundlexem oder Ableitung? Die finnischen Nomina der Typen kämmen und pähkinä und ihre Geschichte. (Studia Fennica. Linguistica 5.) Helsinki: Suomalaisen Kirjallisuuden Seura.

$\mathrm{H}$ a k u $\mathrm{l}$ in e n, Lauri 1968. Suomen kielen rakenne ja kehitys. Kolmas, korjattu ja lisätty painos. Helsinki: Otava.

H e 1 l a t, Peeter 1891. Terwise õpetus. Wälja annud Dr. P. Hellat. Esimene anne. Peeterburis 1891. Trükitud A. Franzscheli juures.

H e 1 l a t, Peeter 1913. Tervise-õpetus. 2. täiend. tr. Peterburi: Ühiselu.

IEW = Julius Pokorny, 1949-1959. Indogermanisches etymologisches Wörterbuch. Bd. I-II. Bern: A. Francke AG. Verlag. 
J u rkat a m, Johan 1904. Wene-Eesti sõnaraamat. Русско-эстонскій словарь. Toim J. Jurkatam. Jurjev (Tartu): K. A. Paar.

K a t z, Hartmut 1990. Bume und Korpsion. Zur Behandlung konsonantischer Anlautkluster in den urgermanischen Lehnwörtern des Ostseefinnischen. (Innsbrucker Studien zur Ural-Altaistik 3.) Innsbruck: Anreiter.

K o p o n e n, Eino 1998. Eteläviron murteen sanaston alkuperä. Itämerensuomalaista etymologiaa. (Suomalais-Ugrilaisen Seuran toimituksia 230.) Helsinki: Suomalais-Ugrilainen Seura.

LEVM = Albert Valdes, Johannes Voldemar Veski 1982-1983. Ladina-eesti-vene meditsiinisõnaraamat I-II. Teadustoim Paul Alvre, Viiu Sillastu. Tallinn: Valgus.

M a c h e k, Václav 1968. Etymologický slovník jazýka českého. Druhé, opravené a doplněné vydání. Praha: Academia nakladatelství, Československé Akademie věd.

M u st, Mari 2000. Vene laensõnad eesti murretes. Toim Lembit Vaba. Tallinn: Eesti Keele Sihtasutus.

M ä g i s t e, Julius 1953. Eräistä suomen ja viron sanoista. - Virittäjä, kd 57, nr 4, lk 360-378.

N i g g o l, Heinrich 1914. Eesti arstiteadusline sõnastik. Tartu: Postimees.

$\mathrm{R}$ a u n, Alo 1982. Eesti keele etümoloogiline teatmik. Rooma-Toronto: Maarjamaa. R e j z e k, Jiř́ 2001. Český etymologický slovník. Voznice: Leda.

R o s e n plänt e r, Johann Heinrich 1818. Uebungsstücke zum Uebersetzen aus dem Ehstnischen ins Deutsche von Joh. Heinr. Rosenplänter. - Beiträge zur genauern Kenntniß der ehstnischen Sprache. Eilftes Heft. Pernau.

S a l e m, Margus 1890. Eesti-vene sõnaraamat. Эстско-русскій словарь. Wiedemanni järele seadnud M. Salem. Täiendanud ja läbi vaadanud J. Kunder ja kooliõpetaja T. Kuusik. Tallinnas: Th. Jakobsoni kirjastus.

SKES IV = Erkki Itkonen, Aulis J. Joki 1969. Suomen kielen etymologinen sanakirja IV. (Lexica Societatis Fenno-Ugricae XII: 4.) Helsinki: Suomalais-Ugrilainen Seura.

SRJA = Словарь русского языка XI-XVII вв. Вып. 25. Москва: Наука, 2000.

SSA = Suomen sanojen alkuperä. Etymologinen sanakirja 1-3. (Kotimaisten kielten tutkimuskeskuksen julkaisuja 62. Suomalaisen Kirjallisuuden Seuran toimituksia 556.) Helsinki: Suomalaisen Kirjallisuuden Seura, Kotimaisten kielten tutkimuskeskus, 1992-2000.

V a b a, Lembit 1997. Par igauṇu hürn 'vaḷiga (spalva)' baltu cilmi. - Baltu filologiija VII. Rīga: Rakstu krājums, lk 140-143.

V a b a, Lembit 2002. Zur Substitution der anlautenden Konsonantenverbindungen im ostseefinnischen Lehnwortschatz (am Beispiel des Estnischen). - FinnoUgrians and Indo-Europeans: Linguistic and Literary Contacts. Proceedings of the Symposiums at the University of Groningen, November 22-24, 2001. Toim Rogier Blokland, Cornelius Hasselblatt. (Studia Fenno-Ugrica Groningana 2.) Maastricht: Shaker, lk 393-400.

$\mathrm{V}$ a b a, Lembit 2014. Über eine mögliche baltische Herkunft von est. varn, fi. vaarna. - Linguistica Uralica, kd L, nr 1, lk 20-28. http://dx.doi.org/10.3176/ lu.2014.1.02

Vanasõnaraamat. Koost Anne Hussar, Arvo Krikmann, Ingrid Sarv. Tallinn: Eesti Raamat, 1984.

V a s m e r I-IV = Макс Фасмер, Этимологический словарь русского языка I-IV. 
Перевод с немецкого и доподнения академика РАН О. Н. Трубачева. Москва: Астрель Аст, 2004.

VMS = Väike murdesõnastik. I-II. Toim Valdek Pall. Tallinn: Valgus, 1982, 1989.

W i e d e m a n n, Ferdinand Johann 1973. Estnisch-deutsches Wörterbuch. Vierter unveränderter Druck nach der von Jakob Hurt redigierten Auflage. Tallinn: Valgus.

\section{Tekstis kasutatud lühendeid:}

$\mathbf{f}=$ feminiin $; \mathbf{m}=$ maskuliin $; \mathbf{n}=$ neutrum $; \mathbf{p l}=$ pluural $; \mathbf{s g}=$ singular .

Murded ja murrakud: (d) = tartu ja võru murre, ka lõunaeesti kirjakeel (Wied); eL = lõunaeesti murded; Hargla; Helme; Kambja; Kanepi; Kodavere; Krl = Karula; Lutsi; MMg = Maarja-Magdaleena; Otepää; Plv = Põlva; Puhja; Rannu; Rõuge; Räpina; $\mathbf{S}$ = saarte murre; Sangaste; Setu; TMr = Tartu-Maarja; Urvaste; Vastseliina; Võnnu.

K e e l e d: asrb = alamsorbi; ee = eesti; $\mathbf{g t ~ = ~ g o o t i ; ~} \mathbf{i}-\mathbf{e}=$ indoeuroopa algkeel; is = isuri; isl = islandi; $\mathbf{k r j}$ = karjala; $\mathbf{k r j A}$ = Aunusekarjala; $\mathbf{k r j} \mathbf{L}$ = Lüüdikarjala; $\mathbf{l a d}$ = ladina $; \mathbf{l m s}=$ läänemeresoome keeled $; \mathbf{n r}=$ norra $;$ pol = poola $;$ slo = slovaki; $\mathbf{s l v n}=$ sloveeni; $\mathbf{s m}=$ soome; $\mathbf{t s ̌ ~ = ~ t s ̌ e h h i ; ~} \mathbf{v d j}$ = vadja; $\mathbf{v i s l}=$ vanaislandi $; \mathbf{v n}=$ vene $\mathbf{v p s}$ = vepsa; vvn = vanavene; üsrb = ülemsorbi.

\section{sarn and sarnane}

Keywords: etymology, Estonian, Finnic languages, Slavic languages

The Estonian sarn 'cheekbone' belongs to the words with still no satisfactory etymology. The same applies to the word sarnane 'similar; coll. such'. Although to-day the word sarn is considered a natural part of the North-Estonian based common and standard language, its historical area of distribution refers it to South Estonian. The word does not occur in other Finnic languages, nor in more distantly related languages. The article suggests a Slavic etymology. The assumed source word is the pre-pleophonic *skorńa, which has descendants in East, West and South Slavic languages, e.g. Russian скоронь f. 'temple', Church Slavonic скрания (-ья) 'cheek; temple; forehead; jaw', скрань 'cheek; cheekbone; side of face; jaw' etc.

The word sarnane has been offered different etymologies. One of them suggests that it has the same root with sarn 'cheekbone'. However, this etymology is called into question by the historical South Estonian distribution of sarn, whereas sarnane occurs all over Estonia. According to the other etymology sarnane has a Finnic-Permic of Finno-Ugric root, with such Finnic descendants as, e.g., Finnish saarna 'sermon', Karelian šoarna 'fairy tale' etc. The semantic relationship has been quite credibly substantiated by Julius Mägiste, arguing that sarnane has originally meant 'in question, similar to the object of talk'.

Lembit Vaba (b. 1945), PhD, Foreign Member of the Latvian Academy of Sciences, phorest45@gmail.com 